\title{
Adherence and quality of life among diabetic patients with hypertension
}

\author{
Akrom Akrom ${ }^{1}$, Wima Anggitasari ${ }^{2}$ \\ ${ }^{1}$ Ahmad Dahlan Drug Informatian and Crisis Center (ADDICC), Indonesia \\ 1,2Pharmacy Faculty, Universitas Ahmad Dahlan, Indonesia
}

\section{Article Info \\ Article history: \\ Received Aug 27, 2018 \\ Revised Nov 12, 2018 \\ Accepted Dec 04, 2018}

\section{Keywords:}

Adherence

Cross sectional study

Diabetic patients

Hypertension

Quality of life

\begin{abstract}
The level of treatment adherence and quality of life are not known in diabetic patients with hypertension. The study aim was to evaluate the level of adherence and quality of life of diabetic patients with hypertension in Bantul Public Hospital (BPH), Bantul, Indonesia. This study used a Cross-sectional method by conducting a survey through a direct interview with the patient. Participants of this study were 143 diabetic patients with hypertension in the internal disease clinic of BPH. Modified Morisky Medication Adherence Scale was used to measure the level of treatment adherence and SF36 questionnaires were used to measure the quality of life. Descriptive and analytical statistical was performed on data from the adherence assessment, quality of life, demographic characteristic and the clinical condition of the research participant. Bivariate analysis with Chi-square was performed to assess the relationship between demographic and clinical factors to the high level of adherence. The majority of respondents had moderate and low levels of adherence. There were 34 patients (23.78\%) with a high level of adherence, 56 patients $(39.16 \%)$ with moderate level of adherence, and 53 patients $(37.06 \%)$ with low level of adherence. Respondents also had low quality of life, in which the average score of quality of life was $61.96 \pm 12.48$. Male and college-educated patients have higher adherence $(O R>1, p<0.05)$ compared to other groups. Medication adherence and quality of life of diabetic patients with hypertension in BPH were relatively low. Male and high college-educated patients were associated with high levels of adherence.
\end{abstract}

Copyright $(2019$ Institute of Advanced Engineering and Science. All rights reserved.

\section{Corresponding Author:}

Akrom Akrom,

Department of Pharmacology and Clinical Pharmacy,

Pharmacy Faculty, Universitas Ahmad Dahlan,

J1. Prof. Dr. Soepomo SH, Janturan, Yogyakarta 55164.

Email: akrom@pharm.uad.ac.id

\section{INTRODUCTION}

Diabetes Mellitus (DM) and hypertension is a public health problem in Indonesia. Hypertension and diabetes mellitus is a chronic disease that requires ongoing medical therapy, in which the incidence is continuously increasing and the success rate of therapy is not satisfying [1-2]. By 2030, the estimated prevalence of DM in Indonesia reaches 21.3 million [3]. DM with hypertension is associated with decreased quality of life [4]. DM with hypertension also increases the risk of heart disease, peripheral vascular disease, and stroke. The prevalence of albuminuria and renal injury is higher in diabetic patients with hypertension compared to diabetic patients without hypertension [5]. DM increases the relative risk of stroke by 6-fold and hypertension increases it up to 4-fold [6]. DM will display a wide range of DM complications when it is not treated properly, such as: neuropathy, nephropathy, retinopathy, hyperlipid, ulcers on the feet, and infection. These complications affect the quality of life of patients with diabetes mellitus. Micro and macrovascular damage due to hyperglycemia and increased levels of HbA1c, lipid metabolism abnormality, accumulation of 
reactive radical, impaired platelet function and blood clotting factors are the responsible factors for the decline in quality of life and the risk of cardiovascular disease in diabetic patients with hypertension [7-8].

Non-adherence in undergoing medication therapy in diabetic patients with hypertension is the key factor that hinders the achievement of therapeutic targets, blood sugar control and blood pressure control. The level of adherence to therapy on diabetic patients with hypertension is estimated to range between $30-50 \%$ [9]. The causes of this non-adherence is very complex, including the complexity of the drug regimen, drug charges, age, gender, lack of social support, education level, type of personality and cognitive problems of the patient [10]. Medication adherence can be measured by using various methods [11-12].

The success in the management of diabetes mellitus is influenced by medication therapy, physical exercise therapy, diet, and other lifestyle changes [13-14]. A more comprehensive approach is required to achieve an intensive control of blood sugar level and optimal blood pressure in diabetic patients with hypertension. It is necessary to avoid complications and decreased the quality of life. Based on that condition, this study aimed to evaluate the quality of life, adherence to medication therapy, and other related factors in diabetic patients with hypertension in Bantul public hospital.

\section{RESEARCH METHOD}

\subsection{Design}

This research was a cross-sectional study among 143 DM with hypertension patients. Data were collected from survey through interviews by using Modified-Adherence Questionnaire (MAQ). M-AQ consisted of eight questions with the response that ranges from 0 to 8. Item 1-7 were yes or no questions. Score value 1 was for the "no" response, and 0 was for the "yes" response, except for item number 5 in which the score value was reversed $(0=$ no and $1=y e s)$. Responses for item 8 were a rating with 5 Likert scale, which values: never $=1$, occasionally $=0.75$, sometimes $=0.5$, and usually $=0.25$, always $=0$. Adherence to therapy level was categorized into three levels: high adherence ( score 8$)$, moderate adherence ( score 6-8) and poor adherence ( score $>6$ ).

It is necessary to check the correlation between the score (value) of each item with the total score of the questionnaire. Meanwhile, validity was tested to determine the extent to which the measurement results could be trusted or relied upon. Reliability showed the degree of consistency from the instrument when it was applied several times on different occasions. The measurement results could be trusted if the instrument was implemented for several times on the same group of subjects and relatively similar results were obtained. This questionnaire has been through pilot testing, validation testing, reliability testing and has been declared as valid and reliable.

\subsection{Participant overview}

The population of this study is diabetic patients with hypertension in internal disease clinic of Panembahan Senopati Bantul Hospital, Yogyakarta during April 2014-May 2015. There are 143 DM with hypertension patients. All participants meet the inclusion and exclusion criteria. The inclusion criteria were: (1) adult patients, both men and women aged 18-60 years old and geriatric patients who could be counseled, (2) diabetic patients with hypertension in the internal disease clinic of Bantul public hospital during the period of the study, (3) patient was diagnosed with level I or level II of diabetes mellitus with hypertension, (4) patients has received medication for diabetes and hypertension, (5) willing to be a participant in the study by completing an informed consent. Meanwhile, the exclusion criteria for this study were: (1) deaf, (2) illiteracy, and (3) pregnant women.

\subsection{Data collection}

This study had been approved by the ethics committee of the University of Muhammadiyah Yogyakarta. The procedures of this research were as follows: (1) patients' data with a clinical diagnosis of diabetes and hypertension were collected from the doctor in the internal disease clinic of Bantul hospital, Yogyakarta, (2) prospective participants were given an explanation about the purpose and the benefit of the research as well as risks that may be received by the participant before the interviewer requested approval as a participant of the research, (3) after obtaining patient' consent to participate in the study, patients were asked to complete and sign the informed consent sheet, (4) patients then asked to fill out a record and assessment of the patient's health (demographic data, habits, history of diseases, and treatments), (5) quality of life and adherence data were obtained through interviews based on the questionnaire. M-AQ was used to assess patient's adherence and the SF-36 questionnaire was used to assess patient's quality of life. Interviews were conducted by personnel that has been specially trained to conduct interviews, (6) data of the patient's clinical condition (results of laboratory examinations, blood pressure examinations, GDS, 
the antihypertensive drug therapy and anti-diabetic therapy) were collected from the medical record and treatment records or prescriptions written on the notes of patient's form.

\subsection{Data analysis}

Data were analyzed by using SPSS 16.0. Data on demographic and clinical characteristics, quality of life scores and level of compliance were presented descriptively. Chi Square was conducted to determine assosciation between age, gender, education, payment or clinical condition with the high level of adherence.

\section{RESULTS AND ANALYSIS}

\subsection{Characteristics of patients}

Demographic characteristics of the patients are shown in Table 1. According to Table 1, total participants of this study were 143 patients. There were 87 female patients $(60.84 \%)$ and there were 56 male patients $(39.16 \%)$. Ninety-one patients were aged less than 60 years $(63.64 \%)$, meanwhile, 52 patients were geriatric patients $(36.36 \%)$. The majority of patients' level of education was high school (53 patients/37.06\%), and the majority of patients were using health insurance as their payment method (115 patients/80.42\%). Most patients were diagnosed with diabetes mellitus and hypertension, but several patients also diagnosed by dyslipidemia (15 patients/10.49\%), uric acid (13 patients/9.09\%) and the combination of both dyslipidemia and uric acid (2 patients/1.40\%).

Table 1. Demographic and clinical characteristics respondent

\begin{tabular}{|c|c|c|}
\hline Variable & Category & $\mathrm{N}(\%)$ \\
\hline \multirow{2}{*}{ Age } & $\leq 60$ & $91(63.64)$ \\
\hline & $>60$ & $52(36.36)$ \\
\hline \multirow{3}{*}{ Gender } & Male & $56(39.16)$ \\
\hline & Female & $87(60.84)$ \\
\hline & Not educated & $3(2.10)$ \\
\hline \multirow{3}{*}{ Level of education } & Elementary or Junior High School & $43(30.07)$ \\
\hline & Senior High School & $53(37.06)$ \\
\hline & University/College & $44(30.77)$ \\
\hline \multirow{2}{*}{$\begin{array}{l}\text { Type of Health } \\
\text { insurance }\end{array}$} & Health insurance & $115(80.42)$ \\
\hline & Non-health insurance & $28(19.58)$ \\
\hline \multirow{3}{*}{ Smoking habit } & Smoking & $19(13.30)$ \\
\hline & Not smoking & $124(86.70)$ \\
\hline & $\mathrm{DM}+\mathrm{HT}$ & $113(79.02$ \\
\hline \multirow{3}{*}{ Clinical Diagnosis } & $\mathrm{DM}+\mathrm{HT}+\mathrm{Dyslipidemia}$ & $15(10.49)$ \\
\hline & $\mathrm{DM}+\mathrm{HT}+$ Uric Acid disorder & $13(9.09)$ \\
\hline & DM+HT+Dyslipidemia+Uric Acid & $2(1.40)$ \\
\hline \multirow{4}{*}{$\begin{array}{c}\text { Type of anti- } \\
\text { diabetes medicine } \\
\text { therapy }\end{array}$} & OAD & $77(53.80 \%)$ \\
\hline & Insulin & $31(21.70 \%)$ \\
\hline & OAD + Insulin & $35(24.50 \%)$ \\
\hline & ACEI & $43(30.10)$ \\
\hline \multirow{6}{*}{$\begin{array}{l}\text { Type of anti- } \\
\text { hypertension } \\
\text { medicine therapy }\end{array}$} & AIRA & $37(25.90)$ \\
\hline & Amlodipine & $62(43.40)$ \\
\hline & Diltiazem & $3(2.10)$ \\
\hline & Nifedipine & $3(2.10)$ \\
\hline & Diuretika & $13(9.10)$ \\
\hline & Beta blocker & $2(1.40)$ \\
\hline \multirow{5}{*}{$\begin{array}{l}\text { Number of } \\
\text { medicine }\end{array}$} & 2 & 40(28.00) \\
\hline & 3 & $69(48.20)$ \\
\hline & 4 & $25(17.50)$ \\
\hline & 5 & $7(4.90)$ \\
\hline & 6 & $2(1.40)$ \\
\hline
\end{tabular}

There were 109 patients (76.2\%) who received 2-3 medicines, while there were only 34 patients (23.8\%) who received 4 or more medicines. There were 77 patients $(53.8 \%)$ who received oral anti-diabetes (OAD) medication therapy, 35 patients $(24.5 \%)$ received OAD combined with insulin therapy and 31 patients $(21.7 \%)$ received insulin therapy. The widely used antihypertensive medications were the calcium antagonists (such as amlodipine, diltiazem, and nifedipine), which was used for 68 patients. 
Meanwhile, other commonly prescribed antihypertensive medication were ACEI in 43 patients (30.1\%), AIRA in 37 patients $(25.9 \%)$ and diuretics in 13 patients $(9.1 \%)$.

\subsection{Clinical characteristic, patients' quality of life and adherence level}

The clinical condition, quality of life and medicine adherence of patient are presented in Table 2 . Table 2 shows that the adherence level of the patient was low (scores=6.27 \pm 1.71 ). In line with this low adherence scores, the average score of the total quality of life was also not satisfying (72.75 \pm 13.40$)$. It indicates that patients had a poor quality of life. The average blood sugar levels of patients were higher than normal $(200.56 \pm 91.97 \mathrm{mg} / \mathrm{dl})$, which showed that the goals of anti-diabetes medicine therapy were not achieved. Physical function and emotional domains of quality of life obtained high scores (>80), but the score of pain, disability and general quality of life domains were low (score=60). These results are in accordance with results of the previous studies [15-17].

\begin{tabular}{|c|c|c|}
\hline Characteristics & Mean \pm SD & (Minimum-Maximum) \\
\hline Clinical Characteristic: Blood Sugar Level $(\mathrm{mg} / \mathrm{dl})$ & $200.56 \pm 91.97$ & $(57.00-603.00)$ \\
\hline Systolic Blood Pressure $(\mathrm{mmHg})$ & $135.70 \pm 17.90$ & $(90.00-180.00)$ \\
\hline Diastolic Blood Pressure $(\mathrm{mmHg})$ & $83.18 \pm 9.99$ & $(60.00-110.00)$ \\
\hline Quality of Life: Score of General Quality of Life & $61.96 \pm 12.48$ & $(29.17-91.67)$ \\
\hline Score of Physical Functioning & $81.75 \pm 18.82$ & $(10.00-100.00)$ \\
\hline Score of Physical Limitation & $61.89 \pm 39.57$ & $(0.00-100.00)$ \\
\hline Score of Emotion Limitation & $77.86 \pm 32.61$ & $(0.00-100.00)$ \\
\hline Score of Social Functioning & $78.25 \pm 22.62$ & $(22.50-100.00)$ \\
\hline Score of Pain & $68.36 \pm 28.76$ & $(0.00-100.00)$ \\
\hline Score of Spirit & $70.82 \pm 14.96$ & $(15.00-100.00)$ \\
\hline Score of Emotions & $81.15 \pm 12.37$ & $(32.00-100.00)$ \\
\hline Total Score of Quality Of Life & $72.75 \pm 13.40$ & $(28.71-98.96)$ \\
\hline Score of Adherence & $6.27 \pm 1.71$ & $(1.50-8.00)$ \\
\hline
\end{tabular}

Adherence levels in anti-diabetes and anti-hypertension medication therapy are presented in Table 3. Table 3 shows that the majority of participants had low until moderate levels of adherence (76.22\%). Meanwhile, there were only 34 patients (23.78\%) with high level of adherence.

Table 3. Adherence level of diabetic patient with hypertension

\begin{tabular}{cccc}
\hline Score of M-AQ & Category & $\mathrm{N}(\%)$ & $p$ \\
\hline$<6$ & Low & $53(37.10)$ & $\mathrm{P}=0.05$ \\
$6-<8$ & Moderate & $56(39.16)$ & \\
8 & High & $34(23.78)$ & \\
Total & & $143(100.00)$ & \\
\hline
\end{tabular}

\subsection{Correlation between age, gender, education, payment method and clinical conditions of patients with medication adherence}

Factors associated with adherence level in anti-diabetes and anti-hypertension medication therapy are presented in Table 4. Table 4 shows that female gender and level of education factors were related to the low level of adherence. Female and low educated (below university) diabetic patient with hypertension have a higher risk $(\mathrm{OR}>1)$ to have a low level of adherence $(>0.05)$ 2.13-fold or 2.2-fold compared to male and college-educated diabetic patient with hypertension. Diabetic patient with hypertension who used health insurance have others clinical diagnosis besides diabetes and hypertension, and who received more than 4 medication therapy have a higher potential of low adherence level (OR $>1)$, although it was not statistically significant $(\mathrm{p}>0.05)$. Patients with insulin therapy have a higher potential to have a low level of adherence $(\mathrm{OR}=0.77)$, although it was not statistically significant $(\mathrm{p}>0.05)$. 
Table 4. Factors related to the level of adherence (Height) of DM patients with hypertension outpatient

\begin{tabular}{|c|c|c|c|}
\hline Variable & Category & OR (CI, $95 \%)$ of high adherence & $\mathrm{P}$ \\
\hline Age & $\begin{array}{l}<=60 \\
>60\end{array}$ & $0.96(0.47-1.93)$ & 0.900 \\
\hline Gender & $\begin{array}{l}\text { Male } \\
\text { Female }\end{array}$ & $0.47(0.23-0.98)$ & $0.030 *$ \\
\hline $\begin{array}{l}\text { Level of } \\
\text { Education }\end{array}$ & $\begin{array}{c}\text { Lower than University } \\
\text { University }\end{array}$ & $2.2(1.01-4.87)$ & $0.046^{*}$ \\
\hline $\begin{array}{l}\text { Health } \\
\text { Insurance }\end{array}$ & $\begin{array}{l}\text { Health Insurance (Askes) } \\
\text { Non-Health Insurance }\end{array}$ & 1.68(CI:0.71 - 3.96) & 0.300 \\
\hline $\begin{array}{c}\text { Clinical } \\
\text { Diagnosis }\end{array}$ & $\begin{array}{c}\mathrm{DM}+\mathrm{HT}+\text { others } \\
\mathrm{DM}+\mathrm{HT}\end{array}$ & 1.97(CI:0.90 - 4.46) & 0.080 \\
\hline $\begin{array}{l}\text { Number of } \\
\text { medication }\end{array}$ & $\begin{array}{c}>4 \\
4 \text { or less }\end{array}$ & 1.39(CI:0.36 - 5.41) & 0.640 \\
\hline $\begin{array}{l}\text { Insulin } \\
\text { Usage }\end{array}$ & $\begin{array}{l}\text { Yes } \\
\text { No }\end{array}$ & $0.77(0.38-1.52)$ & 0.450 \\
\hline
\end{tabular}

*significant difference $(\mathrm{p}<0.05)$

Note: DM=diabetes mellitus; HT=hypertension;

Adherence is a major component in achieving goals of medicine therapy [10]. There are several ways to assess the adherence to medication therapy on diabetic patient with hypertension. One of them is by using the Modified-Morisky Adherence Score (M-MMAS) [11]. Factors associated with adherence in the diabetic patient with hypertension are age, education, patients' knowledge about the medication, patients' knowledge about the diseases, therapies, patient interactions, social environment and economic status [16-18]. Schoberberger et al [19] and Ramli et al [2] showed that the level of adherence is lower in male hypertensive patients. However, a systematic review of several studies on the effect of age, gender, knowledge, and attitudes towards medication adherence gave inconsistent results [20].

Lack of adherence to anti-DM and anti-hypertension medication is associated with decreased quality of life. Uncontrolled blood sugar and blood pressure might bring serious consequences, including the emergence of various complications to diabetes and hypertension, elevated cardiovascular mortality,increased the prevalence of albuminuria, 5-fold higher renal injury risks and increased risk of stroke [21-22]. High level of blood sugar in this study appeared to be related to the decreased quality of life and this result is in line with the previous studies [23]. The efforts of researchers to reduce the occurrence of bias include recruitment of subjects based on criteria; data collection was carried out by trained staff and validated questionnaires used.

\section{CONCLUSION}

It can be concluded that the level of adherence and quality of life in diabetic patient with hypertension were low. Factors associated with low levels of adherence were female gender and low level of education. We suggest to give intervention for improving patient's adherence is necessary so the therapeutic targets can be achieved and patient's quality of life can be improved with the DM and hypertension therapy.

\section{ACKNOWLEDGEMENTS}

The authors would like to say gratitude and reward for all patients and officers of Panembahan Senopati, Bantul District Hospital, Indonesia, for their cooperation during the research.

\section{REFERENCES}

[1] Vijan, S., Sussman, J.B., Yudkin, J.S., Rodney A. Hayward, R.A., Effect of Patients' Risks and Preferences on Health Gains With Plasma Glucose Level Lowering in Type 2 Diabetes Mellitus, JAMA.Intern.Med. 174(8):12271234, 2014

[2] Ramli, Azuana., Ahmad, Nur Sufiza., Paraidathathu., 2012, Medication Adherence Among Hypertensive Patients of Primary Health Clinics In Malaysia, dovepress, Patient Preference and Adherence, 6 613-622., 2012

[3] Depkes, Pharmaceutical Care Untuk Penyakit Hipertensi, Direktorat Bina Farmasi dan Komunitas dan Klinik, Depkes RI, Jakarta, 2007

[4] Redmon B, Caccamo D, Flavin P, Michels R, O’Connor P, Roberts J, Smith S, Sperl-Hillen J. Institute for Clinical Systems Improvement. Diagnosis and Management of Type 2 Diabetes Mellitus in Adults. Updated July 2014

Int. J. Public Health Sci. Vol. 8, No. 1, March 2019: 14 - 19 
[5] Yang, CW., Park, JT., Kim, YL., Lee, YS., Oh, YS., Kang, SW.,2011, Prevalence of Diabetic Nephropaty in Primary Care Type 2 Diabetic Patien with Hypertension: Data From the Korean Epidemiology Study on Hypertension III (KEY III Study), Nephrol Dial Transplant, 26: 3249-3255.

[6] Jozwiak, BP., Bogousslavsky, J., Antihypertensive and Lipid Lowering Treatment in Stroke Prevention: Current State and Future, Acta neurol. Belg., 105: 57-61, 2005

[7] Moran, A.E., Odden, M.C., Thanataveerat, A., Tzong, K.Y., Rasmussen, P.W., Guzman, D. Cost-Effectiveness of Hypertension Therapy According to 2014 Guidelines, NEJM, 372: 447-55, 2015

[8] Epstein, M., Sowers, JR., Diabetes Mellitus and Hypertension, American Heart Association, 19: 403-418, 1992

[9] Wabe, N.T., Angamo MT, Hussein S. Medication adherence in diabetes mellitus and self management practices among type-2 diabetics in Ethiopia, North.Am.J.Med Sci.: 3: 418-423, 2011

[10] Sabate E. Adherence to Long-term Therapies: Evidence for Action. Geneva, Switzerland: World Health Organization; 2003.

[11] Morisky, D.E., Ang A, Krousel-Wood, M.A., Ward H, Predictive Validity of A Medication Adherence Measure in an Outpatient Setting, J. Health-Syst. Pharm, 10:348-54.

[12] McHorney CA1, Zhang NJ, Stump T, Zhao X.2012. Structural equation modelling of the proximal-distal continuum of adherence drivers. Patient Prefer Adherence. 2012;6:789-804. doi: 10.2147/PPA.S36535. Epub 2012 Nov 9.

[13] Palaian, S., Acharya, LD., Rao, PGM., Shanker, PR., Nair, NM., Nair, PN.,2006, Knowledge, Attitude, and Practice Outcome: Evaluating the Impact of Counseling in Hospitalized Diabetic Patient in India, $P \& T$, Vol. 31 No. 7., 2008

[14] AHRQ. Screening for Type 2 Diabetes Mellitus: Systematic Review to Update the 2008 U.S. Preventive Services Task Force Recommendation, AHRQ Publication No. 13-05190-EF-1 October 2014

[15] Obreli-Neto, P.R. Marusic, S. Guidoni, C.M., de Oliveira Baldoni, A., Renovato, R..D., Pilger, D. Cuman, R.K.N., Pereira, L.R.L., Economic Evaluation of a Pharmaceutical Care Program for Elderly Diabetic and Hypertensive Patients in Primary Health Care: A 36-Month Randomized Controlled Clinical Trial, JMCP, Vol. 21, No. 1, 2015

[16] Al-Qasem, A.1., Smith F, Clifford, S. 2011. Adherence to medication among chronic patients in Middle Eastern countries: review of studies. East Mediterr Health J. 2011 Apr;17(4):356-63.

[17] Lemay, J., Waheedi, M., Al-Sharqawi, S., Bayoud, T. 2018. Medication adherence in chronic illness: do beliefs about medications play a role? Patient Prefer Adherence. 2018 Sep 5;12:1687-1698. doi: 10.2147/PPA.S169236. eCollection 2018.

[18] Gomes-Villas Boas, L.C., Pedroso de Lima, M.L.S.A., Pace, A.E. Adherence to treatment for diabetes mellitus: validation of instruments for oral antidiabetics and insulin, Rev. Latino-Am. Enfermagem.;22(1):11-8, 2014 Jan.Feb

[19] Schoberberger R, Janda M, Pescosta W, Sonneek G.,2002, The Compliance Praxis Survey (COMPASS): a multidimensional instrument to monitor compliance for patient on antihypertensive medication. J Hum Hypertens. 2002; 16(11): 779-787

[20] Balkrishnan R., 1998, Predictors of Medication Adherence in the Elderly, Clin Ther, 1998; 20(4):764-771.

[21] Clark, M., Adherence to treatment in patients with type 2 diabetes, Journal of Diabetes Nursing Vol 8 No 10, 2004

[22] Palmer, MJ; Barnard, S; Perel, P; Free, C; (2018) Mobile phone-based interventions for improving adherence to medication prescribed for the primary prevention of cardiovascular disease in adults. The Cochrane database of systematic reviews, 6. CD012675. ISSN 1469-493X DOI: https://doi.org/10.1002/14651858.CD012675.pub2

[23] Bidonde J., Fagerlund B.C., Frønsdal KB Lund UH, Robberstad B. FreeStyle, Libre flash glucose self-monitoring system: a single-technology assessment, Norwegian Institute of Public Health (NIPH), Oslo, NIPH, 2017 